\title{
Digitalizing 360 Degree Employee Competency using Banzhaf Power Index and CDF
}

\author{
J. Mahalakshmi, K. Umadevi
}

\begin{abstract}
Traditionally, 360 degree evaluation of employee competency has been done using ratings given by Subordinates or Direct Reports, Peers, Manager and Self. Based on the rating by all rating group, the competency of the employee is determined. The gap between self-rating and ratings of all other group determines whether an employee has hidden strength or has blind spot in each competency variable. However, whenever larger number of subordinates or peers rates an employee, there is inherent bias and the employee's overall competency rating can be low if the larger group holds grudge against the employee. To avoid bias and determine true rating, this paper proposes innovative use of Banzhaf Power Index. The complete computation and digitalization of Banzhaf Power Index for Chennai based Wind Energy Company is carried out and presented in this paper. The interactive Wolfram Computable Document Format (CDF) has also been created for wider use by personnel managers of other companies.
\end{abstract}

Keywords : 360 degree evaluation, Employee Competency, Banzhaf Power Index, Wolfram Computable Document Format.

\section{INTRODUCTION}

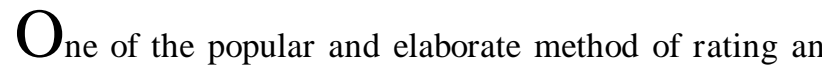
employee's competency is 360 degree evaluation. In this method, the Subordinates (Direct Reports), Peers and Manager rates an employee's competency on a 5 point scale. The employee also rates himself on his competencies. The overall rating of the group determines the final competency score of the employee. However, this method is riddled with many problems, the chief among them being group bias. Whenever large numbers of subordinates or peers rate an employee, there is inherent bias and the employee's overall competency rating becomes low if the larger rating group holds grudge against the employee. In order to overcome this bias and compute true rating, Banzhaf Power Index can be modified to suit the 360 degree evaluation.

The Banzhaf power index or Penrose - Banzhaf index was invented by John F. Banzhaf. It is computed by the probability of changing the outcome of a vote where ever the voting rights are not equally divided among the voters or raters. The Banzhaf power index is only applied for larger rating groups like subordinates and peers since group bias as against individual bias- can stem only from these raters.

Revised Manuscript Received on December 05, 2019.

* Correspondence Author

Dr J. Mahalakshmi, Assistant Professor, PG \& Research Department of Commerce, Guru Nanak College, Velachery, Chennai.

Dr K. Umadevi, Assistant Professor , PG \& Research Department of Commerce, Guru Nanak College, Velachery, Chennai.
This method is applied to competency ratings of 50 employees of Chennai based wind Energy Company. In order to compute the Banzhaf power index and digitalize the entire process, interactive Wolfram Computable Document Format (CDF) has also been created.

\section{REVIEW OF LITERATURE}

The key research literature pertaining to competency mapping and Banzhaf power index which were examined are delineated below :

P. Suguna, T. Tamil Selvi (2013) examined employee Competency Mapping in garment firms in Tirupur district. This study gives concise summary of competency measurements in garment firms and gives a good view of method used to determine competencies in traditional garment manufacturing companies.

S. Balaji \& D. Vimala (2012) carried out Competency Mapping in Adecco Service Organizations, Chennai Asia Pacific and their study elaborates the traditional competency mapping methods in a typical service company.

Su-Chin Hsieh Jui-Shin Lin Hung-Chun Lee (2012) reviewed a large body of international research literature on competency ratings. The meta review gives a very good insight into the practice of competency mapping among international companies.

Y. Nagaraju and V. Sathyanarayana Gowda (2012) examine the strategies of competency mapping in Bangalore companies and contrast the various strategies used.

The Banzhaf related literature which were studied and reviewed includes

B. Llamazares (2006) research focused mathematics of on how difference of votes determines majority.

Matsui, Tomomi and Matsui, Yasuko (2000) reviewed the various algorithms for Calculating Power Indices of Weighted Majority Games which form basis of applying Banzhaf power index to various business situations.

Lehrer, Ehud (1988) in his paper on axiomatization of the Banzhaf Value shows the method of axiomatization using three axioms. None of the papers adopted the Banzhaf power index to evaluate the employee competency which is the reason this paper used Banzhaf power index in an innovative way to remove group rating bias.

\section{OBJECTIVES OF THE STUDY}

The main objectives of this study are:

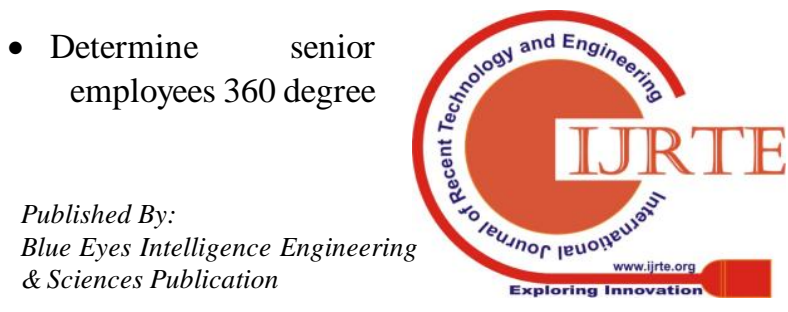


competency ratings for Building Team, Motivating Others, Accountability, Coaching, Communication, Collaborative Leadership, Conflict Management and Service

- Examine if the senior employees competencies show Blind Spot and Hidden Strength

- Compute Banzhaf Power Index for group of 6 rater groups ( 3 Subordinates and 3 Peer raters for each of the 50 employees)

- To create an interactive Banzhaf Power Index Computable Document Format (CDF) for wider use by personnel managers.

\section{RESEARCH METHODOLOGY}

\section{A. Research Design}

This is a descriptive study investigating the competencies of senior employees in Chennai based wind Energy Company.

\section{B. Sample and Sampling Method}

Out of total 62 senior employees in the wind energy company, 50 employees were selected using random sampling method. The employees who had 5 to 10 years' experience in renewable energy industry were considered to be senior employees. The competency rating on 5 point scale for selected 50 employees was obtained from randomly assigned group of 3 Subordinates ( Direct Reports), group of 3 Peers and 1 Manager. Each senior employees' self-rating too was obtained. The ratings were obtained on standard company 360 degree rating form.

\section{Area of Study}

Wind Energy Company in Chennai, Tamilnadu, India.

\section{Data Collection}

360 degree standard 5 point company rating form was used for data collection.

\section{DATA ANALYSIS}

The various methods used for data analysis is described below:

- Competency Rating: The competency rating was given on a 5 point scale. The average rating given by group of 3 Subordinates ( Direct Reports), group of 3 Peers and 1 Manager for each of the 50 senior employee was determined and each variables competency score was determined. The Competency variables and their descriptions are given below:

Table - 1: Competency variables and their description

\begin{tabular}{|c|l|}
\hline $\begin{array}{c}\text { Competency } \\
\text { Variable }\end{array}$ & \multicolumn{1}{c|}{ Description of the Competency variable } \\
\hline Building Team & $\begin{array}{l}\text { Is the employee able to create productive and efficient } \\
\text { workgroups? }\end{array}$ \\
\hline
\end{tabular}

\begin{tabular}{|l|l|}
\hline Motivating Others & $\begin{array}{l}\text { Is the employee creating and sustaining work culture } \\
\text { that encourages subordinates and peers do their best ? }\end{array}$ \\
\hline Accountability & $\begin{array}{l}\text { Is the employee taking responsibility for his/ her } \\
\text { performance and work results? }\end{array}$ \\
\hline Coaching & $\begin{array}{l}\text { Is the employee mentoring others to develop better } \\
\text { team capabilities? }\end{array}$ \\
\hline Communication & $\begin{array}{l}\text { Is the employee able to relay and receive official } \\
\text { communication effectively? }\end{array}$ \\
\hline $\begin{array}{l}\text { Collaborative } \\
\text { Leadership }\end{array}$ & $\begin{array}{l}\text { Is the employee seeking cooperation and feedback } \\
\text { from his peers in decision making process? }\end{array}$ \\
\hline $\begin{array}{l}\text { Conflict } \\
\text { Management }\end{array}$ & $\begin{array}{l}\text { Is the employee able to resolve disagreements } \\
\text { effectively? }\end{array}$ \\
\hline Service & $\begin{array}{l}\text { Is the employee dedication to meet needs of } \\
\text { organizations customers and stack holders? }\end{array}$ \\
\hline
\end{tabular}

Blind Spot: Competencies where self-raters perception are greater than the other raters are called blind spots. This shows the weakness of the employee. It is derived from the difference between the average rating of all groups and self-rating of the employee.

Hidden Strengths: Competencies where other raters perceptions of performance are greater than the self-raters This shows the strength of the employee which he/she is unaware of. It too is derived from the difference between the average rating of all groups and self-rating of the employee.

Banzhaf Power Index: It is determined by the formula

$$
\text { Banzhaf Power Index, } B_{i}=\frac{c_{i}}{\sum_{k=1}^{n} c_{k}}
$$

Where $c_{i}=$ Numberoftimesrater $i$ is critical

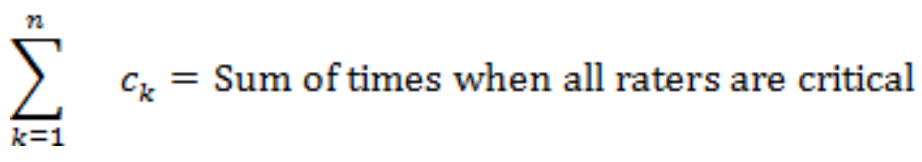

\section{ANALYSIS AND INTERPRETATION}

\section{Competency Analysis}

The Competency rating of all 50 senior employees was collated and average was computed based on 400 data points (50 x 3 Subordinates / Direct Reports, group of 3 Peers x 50, $50 \times 1$ Manager and $50 \times 1$ self-rating).

The results are presented in the following table 
Table - 2: Comprehensive Competency Rating

\begin{tabular}{|c|c|c|c|c|c|c|}
\hline Rating & $\begin{array}{c}\text { Direct } \\
\text { Reports }\end{array}$ & Peers & Manager & Self & All Raters & Perception \\
\hline Overall Rating & 3.5 & 3.5 & 3.6 & 3.6 & 3.53 & Blind Spot \\
\hline Building Team & 3.5 & 3.4 & 3.5 & 3.6 & 3.47 & Blind Spot \\
\hline Motivating Others & 3.5 & 3.5 & 3.6 & 3.6 & 3.53 & Blind Spot \\
\hline Accountability & 3.6 & 3.5 & 3.5 & 3.7 & 3.53 & Blind Spot \\
\hline Coaching & 3.5 & 3.4 & 3.5 & 3.6 & 3.47 & Blind Spot \\
\hline Communication & 3.6 & 3.5 & 3.5 & 3.7 & 3.53 & Blind Spot \\
\hline Collaborative Leadership & 3.5 & 3.5 & 3.6 & 3.6 & 3.53 & Blind Spot \\
\hline Conflict Management & 3.4 & 3.4 & 3.6 & 3.7 & 3.47 & Blind Spot \\
\hline Service & 3.5 & 3.5 & 3.6 & 3.3 & 3.53 & Hidden Strengths \\
\hline
\end{tabular}

From the above table it can be inferred noted that the average Over All competency rating of senior employees is 3.53. Over all, senior employees suffer from Blind spot which indicates that their self-rating of most competency variable is higher than the group rating.

The Building Team competency rating of senior employees is 3.47. Senior employees suffer from Blind spot in this variable too. It indicates that their self-rating of competency variable is higher than the group rating.

In Motivating others, competency rating of senior employees is 3.53 . Here too the senior employees suffer from Blind spot. It indicates that their self-rating of this competency variable is higher than the group rating.

In case of Accountability, competency rating of senior employees is 3.53 . Here too the senior employees suffer from Blind spot. It indicates that their self-rating of this competency variable is higher than the group rating.

When it comes to coaching, competency rating of senior employees is 3.47 . Here too the senior employees suffer from Blind spot. It indicates that their self-rating of this competency variable is higher than the group rating.

As far as Communication is concerned, competency rating of senior employees is 3.53. The senior employees suffer from Blind spot in this competency too. It indicates that their self-rating of this competency variable is higher than the group rating.

Rating of Collaborative Leadership indicates that competency rating of senior employees is 3.53. The senior employees suffer from Blind spot in this competency too. It indicates that their self-rating of this competency variable is higher than the group rating.

Conflict Management rating indicates that competency rating of senior employees is 3.47. The senior employees suffer from Blind spot in this competency too. It indicates that their self-rating of this competency variable is higher than the group rating.

Service is the only competency which indicates hidden strength of the senior employees with rating of 3.53. It indicates that their self-rating of this competency variable is lower than the group rating. Hence they perceive themselves to be less competence than what other rates perception.

\section{Competency Gap Analysis:}

The competency gap analysis of the senior employees are depicted in the radar chart below. The radar chart comprehensively depicts the difference in self and other group ratings.

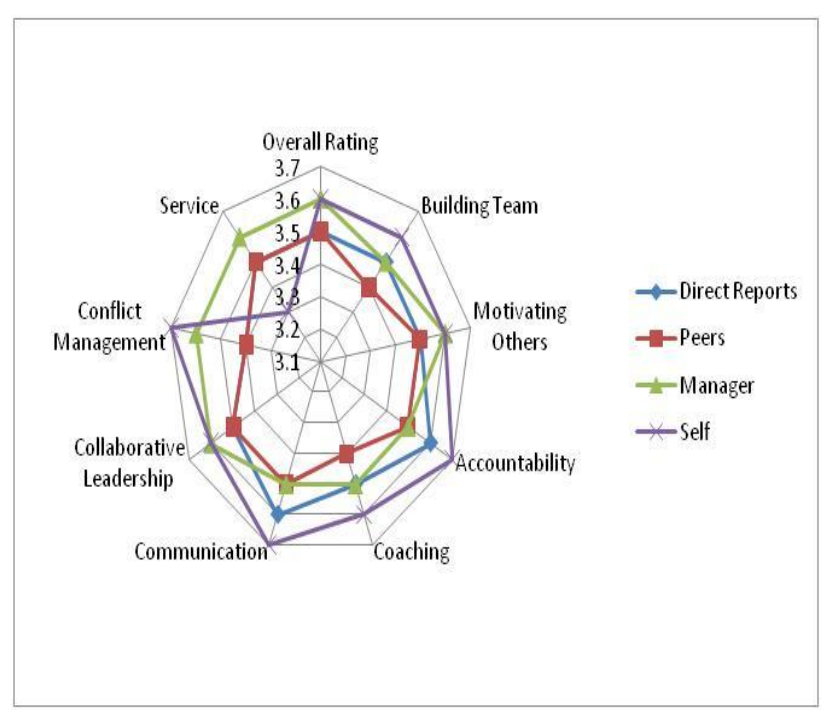

Figure - 1: Comprehensive Competency Rating Gap Analysis

It can be noted from the above figure that Self rating is higher than all other rating for all competency variables except Service competency variable. Peers have given lower rating in most of the competency variables than other groups. The Radar chart clearly shows that the employees have to strive hard to overcome the lower perception on competencies as determined by their Subordinates, peers and managers.

\section{Banzhaf Power Index Analysis:}

The Banzhaf Power index is computed based on group of 3 subordinate rating and group of 3 peer ratings. In order to compute the Banzhaf Power Index and digitalize the process, an interactive Computable Document Formatwas created with Wolfram Mathematicia Version 11.0 by the authors based on Seth J. Chandler's code.

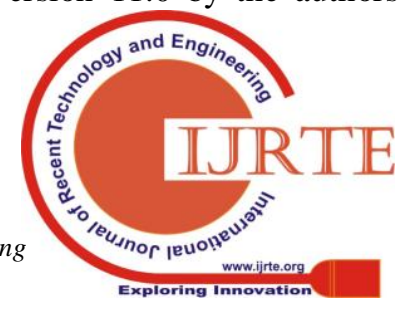


In order to remove the group bias in the competency the computed Banzhaf Power Index is shown below. ratings, Banzhaf Power Index is calculated. The percentage needed to declare competency is set at 0.508 and raw rating is set same for all the raters. With the aforementioned settings,

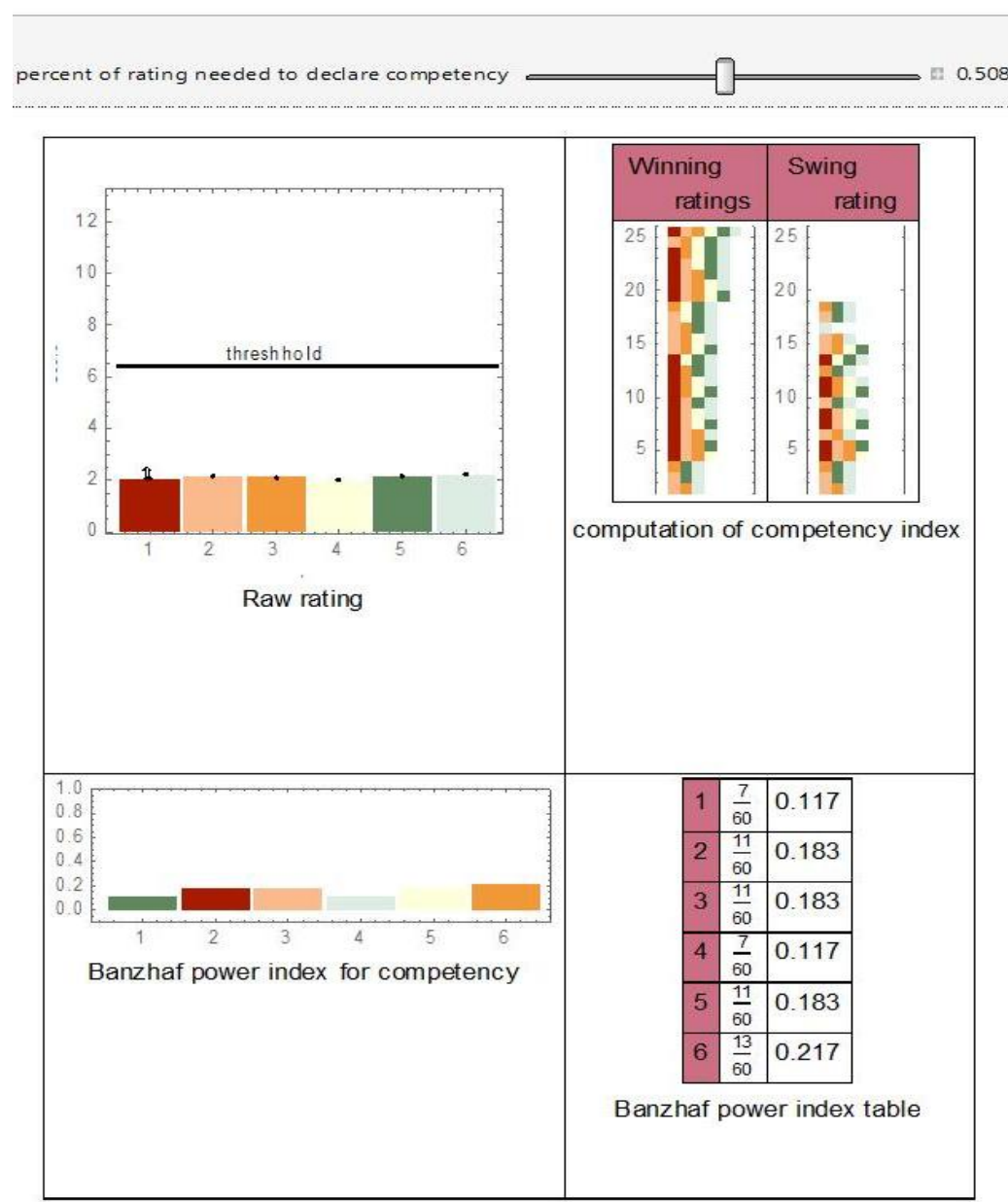

Figure - 2: Banzhaf Power Index for Equal Raw Rating

The Banzhaf Power Index for aforementioned setting is tabulated below:

Table 3: Banzhaf Power Index for Equal Raw Rating

\begin{tabular}{|c|c|c|}
\hline Raters & Raw Rating & $\begin{array}{c}\text { Banzhaf Power } \\
\text { Index }\end{array}$ \\
\hline Subordinate1 & 2 & 0.117 \\
\hline Subordinate2 & 2 & 0.183 \\
\hline Subordinate3 & 2 & 0.183 \\
\hline Peers1 & 2 & 0.117 \\
\hline Peers2 & 2 & 0.183 \\
\hline Peers3 & 2 & 0.217 \\
\hline
\end{tabular}

It can be inferred from the above table that Subordinate 1 and Peers1 have the lowest Banzhaf Power Index of 0.117 hence ratings of these two can be included in the Competency Rating to remove Group bias.

Similarly, if the percentage needed to declare competency is set at 0.508 and raw rating is set at 6 for 1 st Subordinate and 7 for 2nd Subordinate, and 1 for all the raters computed Banzhaf Power Index changes. The results are tabulated below:
Table 4: Banzhaf Power Index for Unequal Raw Rating

\begin{tabular}{|c|c|c|}
\hline Raters & $\begin{array}{c}\text { Raw } \\
\text { Rating }\end{array}$ & $\begin{array}{c}\text { Banzhaf Power } \\
\text { Index }\end{array}$ \\
\hline Subordinate1 & 6 & 0.2 \\
\hline Subordinate2 & 7 & 0.44 \\
\hline Subordinate3 & 1 & 0.12 \\
\hline Peers1 & 1 & 0.12 \\
\hline Peers2 & 1 & 0.12 \\
\hline Peers3 & 1 & 0 \\
\hline
\end{tabular}

It can be noted from the above table that Subordinate 3 and Peers 1 and 2 have the lowest Banzhaf Power Index of 0.12 hence ratings of these three can be included in the Competency Rating to remove Group bias. It should be noted that Peer 3 has zero Banzhaf Power index and can be ignore for modified Competency rating.

The complete statistics of Banzhaf Power Index with Winning Rating, Swing rating, Banzhaf Power Index table and chart is depicted below in Figure 3. 

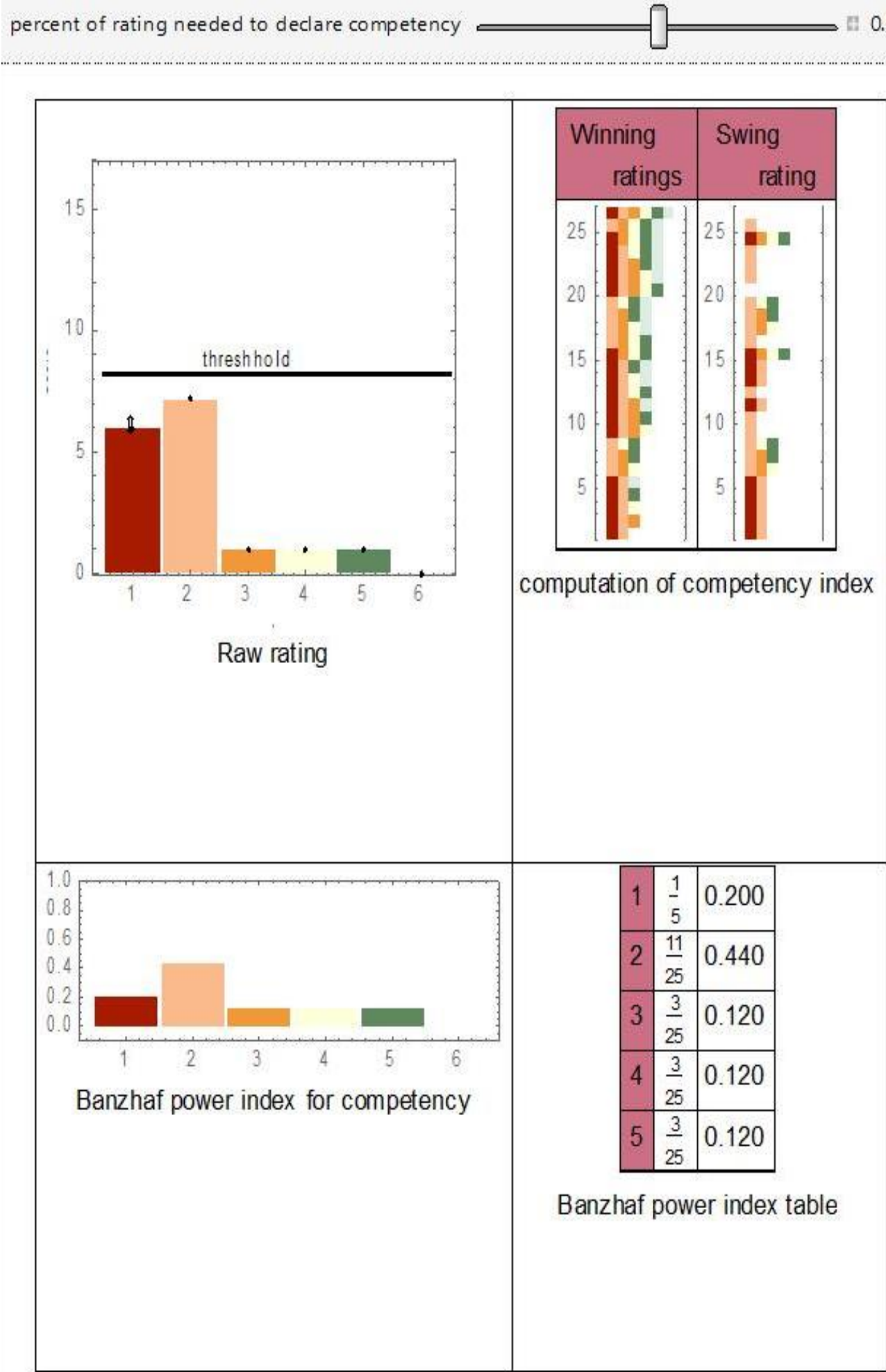

Figure 3: Banzhaf Power Index for Unequal Raw Rating

The computation of Banzhaf Power index has thus been digitalized for easy Competency rating without bias. Any value of raw rating can be assigned and computation can be carried out.

\section{Interactive Banzhaf Power Index Computable Document} Format:
To make the entire Banzhaf Power Index general and digitalized for use by Personnel manager, interactive Banzhaf Power Index was created in computable document format by the authors.

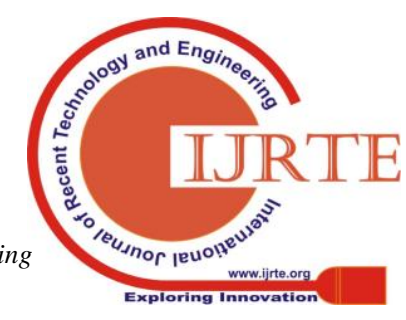



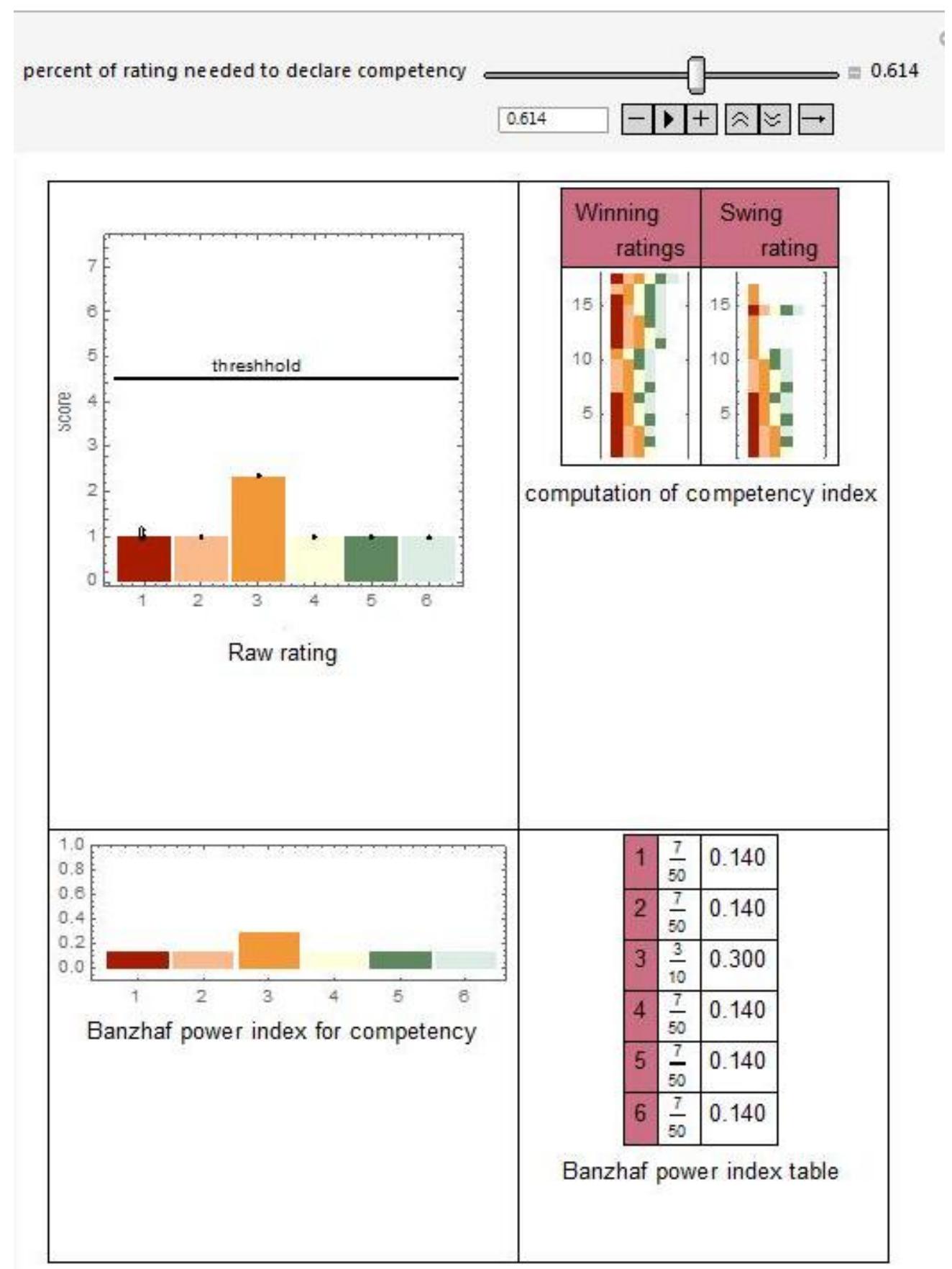

Figure 4: Screen Shot of Interactive Banzhaf Power Index

\section{The features of interactive Banzhaf Power Index include}

- Manipulate Percentage of rating needed to declare competency using slider range from 0 to 1

- Manipulate each of the 6 Raw rating using bar chart handles

- Auto computation of Banzhaf Power index chart and Index.

\section{FINDINGS}

\section{The major findings of the study are summarized below}

- Over All competency rating of senior employees is 3.53. Over all, senior employees suffer from Blind spot which indicates that their self-rating of most competency variable is higher than the group rating.

- Service is the only competency which indicates hidden strength of the senior employees with rating of 3.53. It indicates that their self-rating of this competency variable is lower than the group rating. Tthey perceive themselves to be less competence than what other rates perception.

- Gap Analysis too indicates that that Self rating is higher than all other rating for all competency variables except Service competency variable. Peers have given lower rating in most of the competency variables than other groups. Employees have to strive hard to overcome the lower perception on

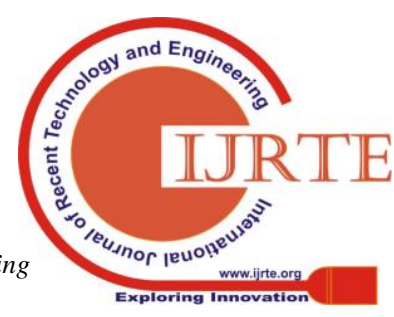


competencies as determined by their Subordinates, peers and managers.

- When the percentage needed to declare competency is set at 0.508 and raw rating is set same for all the raters, Subordinate 1 and Peers 1 have the lowest Banzhaf Power Index of 0.117 .

- When percentage needed to declare competency is set at 0.508 and raw rating is set at 6 for 1 st Subordinate and 7 for 2nd Subordinate, and 1 for all the raters computed Banzhaf Power Index changes, Subordinate 3 and Peers 1 and 2 have the lowest Banzhaf Power Index of 0.12.

- The computation of Banzhaf Power index works with digitalized interactive CDF for easy Competency rating without bias. Any value of raw rating can be assigned and computation can be carried out.

\section{CONCLUSION}

The major problem of group bias in 360 degree competency rating was comprehensively neutralized by innovative use of Banzhaf Power Index. The complete computation and digitalization of Banzhaf Power Index for Chennai based Wind Energy Company was carried out and presented in this paper. It can be concluded that the interactive Banzhaf Power Index Computable Document Format $(\mathrm{CDF})$ has wide ranging uses in any rating where voter based bias can creep in. The methodology used in this paper can be generalized and can be applied across industry for rating employees. The ease of interactive computable document can lead to faster digitalization of the entire rating process. There is no doubt that an important tool for personnel managers for employee evaluation has been created and tested successfully by methodology used in this paper.

\section{REFERENCES}

1. B. Llamazares (2006)."The forgotten decision rules: Majority rules based on difference of votes".Mathematical Social Sciences, $51: 311-326$

2. Dr. Y. Nagaraju and V. SathyanarayanaGowda (2012). "A Study of employee competency mapping strategies at select organization of Bangalore". International Journal Of Research In Commerce And Management, Issue No. 10.

3. Dr.P.Suguna, T.TamilSelviMay (2013) Competency Mapping. "A Drive for Garment Firms in TirupurDistrict". International Journal of Scientific and Research Publications, Volume 3, Issue 5.

4. Lehrer, Ehud (1988). "An Axiomatization of the Banzhaf Value" (PDF). International Journal of Game Theory. 17 (2): 89-99.

5. Matsui, Tomomi; Matsui, Yasuko (2000). "A Survey of Algorithms for Calculating Power Indices of Weighted Majority Games"

6. S. Balaji \& D. Vimala (2012). “A Study On Competency Mapping In Adecco Service Organizations, Chennai Asia Pacific”. Journal of Marketing \& Management Review Vol.1 No. 3, ISSN 2319-2836

7. Su-Chin Hsieh Jui-Shin Lin Hung-Chun Lee October (2012).” Analysis on Literature Review of Competency".International Review of Business and Economics Vol.2

\section{AUTHORS PROFILE}

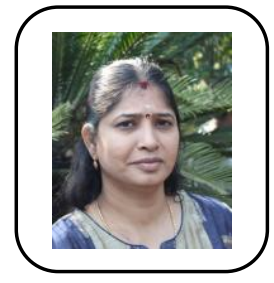

Dr.J.Mahalakshmi, M.Com., M.Phil., M.B.A., M.F.M., SET., Ph.D. is Assistant Professor in PG and Research Department of Commerce in Guru Nanak College, Chennai. Her core area of research interest is Human Resource Management and Finance. She has 15 years teaching experience, of which 5 years are at Post Graduate level. She has published 12 articles in National and International journals with high impact factor. She has presented and participated in National and International Conferences, Seminars and has attended many workshops. She is Vice President-PG of Commerce Association. She is also Board of Examiner for University of Madras, UG External Examiner and Question paper setter for Autonomous colleges and University in Tamilnadu. She is also approved MBA Project Guide for University of Madras and Alagappa University, Resource person for University of Madras and Madurai Kamaraj University Distance MBA Programme.

Dr. K. Umadevi, MCom, MPhil, MBA, PGDHE ,SET, Ph.D. is Assistant

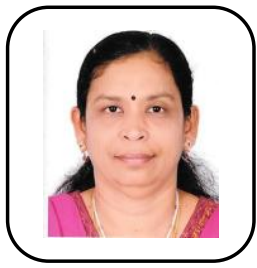
Professor in PG and Research Department of Commerce in Guru Nanak College, Chennai. She has teaching experience of over 25 years of which 13 years are dedicated to Postgraduate teaching. She has been conferred "Best Faculty Award" by GRABS Educational Charitable Trust for the year 2018. In the Republic Day Achievers Award (2018) ceremony, she was conferred" Best Faculty Commerce - HRM for the year 2017" by Integrated Intelligent Research. She is Ph.D. Research Supervisor for Madras University and is also approved guide for MBA course for IGNOU, Madras University and Annamalai University for over a decade. She has contributed over 40 research articles in National and International Journals with high impact factor and has presented papers at National and International conferences and Seminars. She has authored two text books on Business communication and Business Management. A member of Board of studies, Question Paper setter and Evaluator for colleges in Tamil Nadu. She is a member of planning and working committee in IQAC, Coordinator of Women Student Forum, Editor of Guru Nanak Journal of Multidisciplinary Research (GNJMR) and for the newsletter "Banyan Enclave". She was the Placement Coordinator and has successfully coordinated with many MNCs and local companies to place students in various positions. 


\begin{abstract}
APPENDIX
Banzhaf Power Index Code for Interactive CDF (based partially on Seth J. Chandler's code) Manipulate[Module[\{heights=Last/@ $\{\operatorname{loc} 1, \operatorname{loc} 2, \operatorname{loc} 3, \operatorname{loc} 4, \operatorname{loc} 5, \operatorname{loc} 6\}, \mathrm{b}, \mathrm{t}\}$,

$\mathrm{t}=$ Total[heights]*pct;

$\mathrm{b}=$ banzhafData[Range[Length[heights]], heights,t];

Grid[ $\{\{$ Labeled[Graphics[ $\{$ MapIndexed[ \{ColorData[27][\#2[[1]]],Rectangle[ [\{\#2[[1]]-0.47,0\},\{\#2[[1]]+0.47,\#\}]\}\&,heights] ,Thickness[0.01],Line[ $\{\{0.5, \mathrm{t}\},\{$ Length[heights]+0.5,t $\}\}]$, Text["threshhold", $\{$ Length[heights]/2,t $\},\{0,-1\}]\}$, AspectRatio-> 1,Frame-> True,FrameLabel-> "voter","Score" $\}, P l o t R a n g e->\{\{0.3$, Length[heights]+0.6\},\{-0.1,Total[heights]*1.05 $\}\}, I m a g$ eSize-> 250,ImagePadding-> $\{\{25,25\},\{25,25\}\}]$,Text@ "Raw rating"],

Labeled[Text@Grid[ $\{\{$ "Winning ratings","Swing

rating" $\},\{$ Graphics[MapIndexed[\{ColorData[27][\#],Rectangle[Reverse@\#2]\}\&,b[[1]],\{2\}],Frame-> FFalse,True $\}, P l o t R a n g$ e-> $\{\{0,8\},\{1,1+$ Length[b[[1]]]\}\}],Graphics[MapIndexed[\{ColorData[27][\#],Rectangle[Reverse@\#2]\}\&,b[[2]],\{2\}],Frame

-> False,True $\},$ PlotRange-> $\{\{0,8\},\{1,1+$ Length $[\mathrm{b}[[1]]]\}\}]\}\}$, Background- $>\{$ None, $\{$ ColorData[27][0.5]\}\},Dividers->All,It emSize->\{6,1\}],Text@"computation of competency

index"]\},\{Labeled[Graphics[\{MapIndexed[\{ColorData[27][\#2[[1]]],Rectangle[\{\#1[[1]]-0.47,0\},\{\#1[[1]]+0.47,\#1[[2]]\}]\}\& ,b[[3]]]\},Frame-> True,PlotRange-> $\{\{0.3$,Length[heights]+0.6\},\{-0.1,1\}\},ImageSize->250,AspectRatio-> 1/3],Text@ "Banz haf power index for

competency"],Labeled[Text@Grid[Sort[Map[Append[\#,NumberForm[N@\#[[2]],\{4,3\}]]\&,b[[3]]]],Dividers->All,Backgrou nd-> \{ $\{$ ColorData[27][0.3]\},None $\}]$, Text@"Banzhaf power index

table"] \} \},Dividers->All,ItemSize-> \{Automatic, $\{30,20\}\}$,Alignment-> \{Center,Top $\}]],\{\{$ pct, 0.6666, percent of rating needed to declare

competency" $\}, 0.001,1,0.001$,Appearance->"Labeled" $\},\{\{$ loc $1,\{1,1\}\},\{1,0\},\{1,10\}$, Locator,Appearance->Graphics[ $[\{$ Point [ $\{0,0\}], \operatorname{Text}[" \backslash[$ DoubleUpDownArrow]", $\{0,0\}]\}]\}$,

$\{\{\operatorname{loc} 2,\{2,1\}\},\{2,0\},\{2,10\}$, Locator,Appearance->Graphics[Point $[\{0,0\}]]\},\{\{\operatorname{loc} 3,\{3,1\}\},\{3,0\},\{3,10\}$, Locator,Appearanc e->Graphics[Point $[\{0,0\}]]\}$,

$\{\{\operatorname{loc} 4,\{4,1\}\},\{4,0\},\{4,10\}$, Locator,Appearance->Graphics[Point $[\{0,0\}]]\}$,

$\{\{\operatorname{loc} 5,\{5,1\}\},\{5,0\},\{5,10\}$, Locator,Appearance->Graphics[Point $[\{0,0\}]]\}$,

$\{\{\operatorname{loc} 6,\{6,1\}\},\{6,0\},\{6,10\}$, Locator,Appearance->Graphics[ $[$ Point $[\{0,0\}]\}]\}$, TrackedSymbols-> $\{$ loc 1,loc2,loc3,loc4,loc5,1 oc6,pct \},SaveDefinitions-> True]
\end{abstract}

Interactive cdf Available at: https://drive.google.com/open?id=1HfTmnZBN6mZXsBh7WhgTFYAhz616xIzw (requires free cdf plugin from Mathematica) 